\title{
Breaking the stigma of retraction
}

\author{
Retractions are a key tool for maintaining the integrity of the published record. We need to recognize and reward \\ researchers, especially early-career researchers, who do the right thing in coming forward with a request to retract \\ research that cannot be relied upon due to honest error.
}

$\mathrm{t}$ is by now common knowledge that, although retractions are overall rare, they have become much more frequent in the new millennium. Despite initial alarm, it is also now understood that this is actually a good thing rather than a sign of rampant fraud $^{1}$ : the result of intensified efforts by journals, scientists and other actors (such as the Committee on Publication Ethics or initiatives such as Retraction Watch) to take active steps in a systematic way to 'clean up' the published record and safeguard its integrity.

Retraction, though, is a fraught term. It has come to be associated with recrimination and stigma. In the mind of many scientists and the public, it is filled with blame and reproach. This is mainly due to the fact that, although retractions are meant to be a neutral tool for correcting the record and removing papers whose conclusions no longer stand, they have come to be associated with fraud or misconduct.

The truth is that while some retractions arise because of wrongdoing, many do not. An analysis of retractions in the journal Science during the period 1983-2017 found that $51 \%$ of papers had been retracted owing to honest error ${ }^{2}$. Similarly, Brainard ${ }^{1}$ reported that almost $40 \%$ of retractions in the then newly released Retraction Watch Database appeared to be instances of honest error. Retracting a paper voluntarily to correct an honest mistake is a mark of scientific integrity, but the term 'retraction' doesn't distinguish these from cases of intentional misbehaviour, which tend to (rightly) make for attention-grabbing headlines in both the popular and scientific press.

When you discover an error in one of your published papers, you have two choices: come forward or stay silent and hope nobody else notices. The first option has a substantial potential cost associated

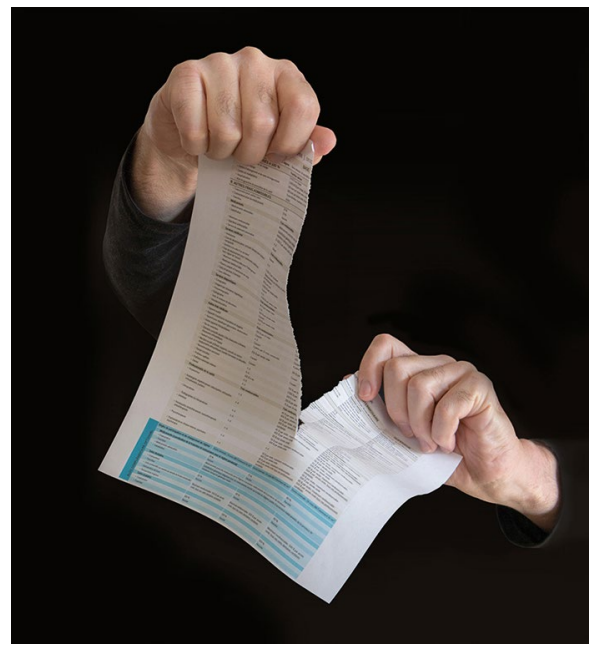

Credit: f:nalinframe / Alamy Stock Photo

with it. For established researchers, it can ignite suspicion and may affect how the quality of all of your previous work is perceived ${ }^{3}$. If you are an early-career researcher, the cost is even higher and may even affect your chances of having a career in academia. Existing recognition and reward structures offer no external incentive to come forward and request a retraction of your paper upon discovering a fatal honest error. Those who come forward do so out of an internal sense of responsibility that outweighs strong external disincentives.

In this issue, we feature a World View by an early-career researcher who did the right thing, despite the potentially outsized cost of doing so. The process for Joana Grave was agonizing, but she was unwavering - when she discovered an error in her first and only published paper, she did all the right things and received all the right support, both from her advisors and the scientific Twitter sphere. But how many early-career scientists would have done the same? And even if they were inclined to do so, how many advisors would be equally supportive? The potential cost is high and in these circumstances it is difficult to pass judgement on those less brave.

Retractions are a tool for correcting the literature - not a verdict on moral character. There are numerous calls to change both the practices and terminology used for correcting the literature when an article's conclusions are not reliable (for example, ref. ${ }^{4}$ ). These are important calls that journals and the scientific community need to work together to resolve. At the same time, institutions worldwide also have established processes for dealing with research misconduct and meting out sanctions. However, what is much less discussed - let alone acted upon - is how to change recognition structures to reward scientists for doing the right thing.

We not only need to combat the stigma associated with retractions due to unintended error (which dis-incentivizes scientists and journals from retracting articles when necessary), but also to identify ways to formally recognize and reward researchers - especially early-career ones - who come forward and initiate the retraction of their own work when they discover fatal errors that undermine their conclusions. We cannot rely on an inner sense of integrity and responsibility alone to drive this process, given that the cost may well be driving these scientists out of the scientific community.

Published online: 16 December 2021 https://doi.org/10.1038/s41562-021-01266-7

References

1. Brainard, J. Science 362, 390-393 (2018).

2. Wray, K. B. \& Andersen, L. E. Scientometrics 117, 2009 (2018).

3. Azoulay, P., Bonatti, A. \& Krieger, J. L. Res. Policy 46, 1552-1569 (2017).

4. Barbour, V., Bloom, T., Lin, J. \& Moylan, E. F1000 Res. 6 1960 (2017). 